\title{
Microstructural Characteristics with Various Finish Rolling Temperature and Low Temperature Toughness in Hot Rolled Nb-Ti Ferritic Steel
}

\author{
Fengqin JI, ${ }^{*}$ Chengning LI, Shuai TANG, Guo YUAN and Guodong WANG \\ The State Key Laboratory of Rolling and Automation, Northeastern University, P.O. Box. 105, No. 11, Lane 3, Wenhua Road, \\ Heping District, Shenyang, 110819 China.
}

(Received on May 29, 2015; accepted on December 24, 2015)

\begin{abstract}
In order to investigate the effects of finish rolling temperature on the microstructural characteristics and fracture mechanism of $\mathrm{Nb}-\mathrm{Ti}$ ferritic steel, the samples with various finish rolling temperature have been observed by optical microscopy, scanning electron microscopy, electron backscatter diffraction and transmission electron microscopy. The results indicated that both ferrite grain size and volume fraction of $(\mathrm{Nb}, \mathrm{Ti}) \mathrm{C}$ precipitates decreased with the decreasing finish rolling temperature, but the size of $(\mathrm{Nb}, \mathrm{Ti}) \mathrm{C}$ precipitates changed little with the finish rolling temperature. All of these factors caused the yield strength, tensile strength and elongation remained similar. However, the low temperature toughness was significantly influenced by the finish rolling temperature. Based on the observation results of fracture surface of samples tested at $-40^{\circ} \mathrm{C}$, the fracture type of steels with finish rolling temperature of $940^{\circ} \mathrm{C}$ and $910^{\circ} \mathrm{C}$ was brittle, while the fracture of steel with finish rolling temperature of $880^{\circ} \mathrm{C}$ was ductile. At last, the crack initiation and propagation mechanism is elucidated in details. At $-40^{\circ} \mathrm{C}$, both intergranular cracks and transgranular cracks existed in the steels finish rolled at $940^{\circ} \mathrm{C}$ and $910^{\circ} \mathrm{C}$, and only microvoides were observed in the steel finish rolled at $880^{\circ} \mathrm{C}$ with high toughness.
\end{abstract}

KEY WORDS: microstructural characteristics; finish rolling temperature; fracture mechanism; Nb-Ti steel.

\section{Introduction}

Hot rolled high strength low alloy (HSLA) steels are widely used in the automobile steels, which require high strength to ensure the safety norms and reduce the weight of car bodies for fuel efficiency. Additionally, good ductility is very crucial for the complicated forming process. ${ }^{1-3)}$ However, the ductility often reduces with the increasing strength. Therefore, it is difficult to obtain the combination of high strength and excellent ductility. ${ }^{4,5)}$ Nanohiten, the (Ti,Mo)C precipitation hardened high strength hot rolled steel sheet developed by JFE corporation, ${ }^{6,7)}$ implemented the balance between strength and ductility, with high cost of molybdenum addition.

Unlike the addition of titanium and molybdenum, both niobium and titanium added to HSLA steels can obtain grain refinement and precipitation strengthening. ${ }^{8)}$ Recently, a number of researchers have studied $\mathrm{Nb}-\mathrm{Ti}$ microalloyed steels. The influence of deformation temperature on recrystallization and precipitation behavior in austenite was investigated by Kostryzhev et al. ${ }^{9,10)}$ The study on the effects of deformation temperature and cooling rate on the continuous cooling transformation elucidated the relationship between transformation driving force, deformation temperature and

\footnotetext{
* Corresponding author: E-mail: fengnieqinxi@163.com DOI: http://dx.doi.org/10.2355/isijinternational.ISIJINT-2015-297
}

cooling rate. ${ }^{11,12)}$ Misra et al. ${ }^{13)}$ developed a $770 \mathrm{MPa}$ hot rolled $\mathrm{Nb}$-Ti steel consisting of fine ferrite grains, bainite and four types of precipitations. Hu et al. ${ }^{14)}$ developed a hot rolled $\mathrm{Nb}-\mathrm{Ti}$ bainitic high strength steel composed of granular bainite and a small amount of polygonal ferrite with $\mathrm{M} / \mathrm{A}$ islands. Additionally, the isothermal precipitation behaviors of $(\mathrm{Nb}, \mathrm{Ti}) \mathrm{C}$ in ferrite and bainite phases were also explored. ${ }^{15-17)}$ Finish rolling temperature plays a more critical role in grain refinement and precipitation strengthening, compared with the coiling temperature which influences just precipitation strengthening. ${ }^{5,18)}$ Besides finish rolling temperature, cooling rate after hot rolling also significantly influences grain size and precipitation behavior, and ultra fast cooling (UFC) technology is used to obtained higher strength steel. ${ }^{19,20)}$ Compared with the normal cooling after hot rolling, UFC can effectively suppress the growth of austenite grain and refine the size of ferrite grain and precipitation. Tang et $a l^{20)}$ reported that the yield strength of hot rolled microalloyed steels can be increased by more than $100 \mathrm{MPa}$ by using UFC over conventional accelerated cooling, which is associated with grain refinement and precipitation. Besides the strength of microalloyed steels, the grain refinement and precipitation may also play an important role in toughness. However, it is lack of detailed studies regarding effects of finish rolling temperature on microstructure and mechanical properties in $\mathrm{Nb}-\mathrm{Ti}$ microalloyed high strength steels with UFC cooling condition after hot rolling. 
In this study, we explored how the finish rolling temperature influences the microstructure and mechanical properties of a $\mathrm{Nb}-\mathrm{Ti}$ hot rolled steel by controlling the rolling conditions followed by UFC. Microstructural analyses were made focusing on grain refinement and precipitation hardening. The relationship between low temperature toughness and finish rolling temperature was also discussed. Eventually, the fracture mechanism of specimens with different microstructures was elucidated based on the fracture surface and the cracks initiation and propagation.

\section{Experimental Procedure}

A microalloyed steel slab with the chemical composition 0.05C, 0.22Si, 1.50Mn, 0.025Nb, 0.11 Ti, 0.058Al, 0.0045P, $0.0018 \mathrm{~S}$ and $0.004 \mathrm{~N}$ (all wt pct) was vacuum melted and cast as $160 \mathrm{~kg}$ ingots, and cut into square billets measuring $90 \mathrm{~mm}$ long, $70 \mathrm{~mm}$ wide and $45 \mathrm{~mm}$ thick. These billets were used as feedstock material for laboratory rolling trials using a $\Phi 450 \mathrm{~mm}$ two hi-rolling mill. A schematic illustration of the rolling and cooling conditions is shown in Fig. 1. The billets were reheated at $1250^{\circ} \mathrm{C}$ for $2 \mathrm{~h}$, in order to ensure the dissolution of $\mathrm{Nb}$ and Ti elements, followed by air cooling to the start rolling temperature of $960^{\circ} \mathrm{C}$, and rolled by seven passes with exit thicknesses of F1 $34 \mathrm{~mm}$, F2 26 $\mathrm{mm}, \mathrm{F} 320 \mathrm{~mm}, \mathrm{~F} 415 \mathrm{~mm}, \mathrm{~F} 511 \mathrm{~mm}, \mathrm{~F} 68 \mathrm{~mm}$ and F7 6 $\mathrm{mm}$, respectively. The inter-pass time of F1/F2, F2/F3, F4/ F5, F5/F6 were about 2-3 seconds. During the inter-pass of F3/F4 and F6/F7, the plates were air cooled to control the F4 temperature and $\mathrm{F} 7$ temperature (finish rolling temperature). The F4/F7 temperatures for three plates were $950^{\circ} \mathrm{C} / 940^{\circ} \mathrm{C}$, $930^{\circ} \mathrm{C} / 910^{\circ} \mathrm{C}$ and $920^{\circ} \mathrm{C} / 880^{\circ} \mathrm{C}$, respectively. After finish rolling, the plates were immediately cooled to the coiling temperature $620^{\circ} \mathrm{C}$ at a rate of $80^{\circ} \mathrm{C} / \mathrm{s}$ by ultra fast cooling. Coiling was simulated by slow cooling in the furnace to room temperature. For convenience, the steel specimens are referred to as A940, A910 and A880, respectively.

The specimens were characterized for grain-size distribution using optical image analysis on a minimum of 200 grains on specimens ground, polished, etched with $4 \%$ natal for approximately 10 to 15 seconds, and observed using Leica DMIRM optical microscopy. Grain boundary carbide distributions were observed on etched specimens in field emission scanning electron microscopy (ZEISS ULTRA

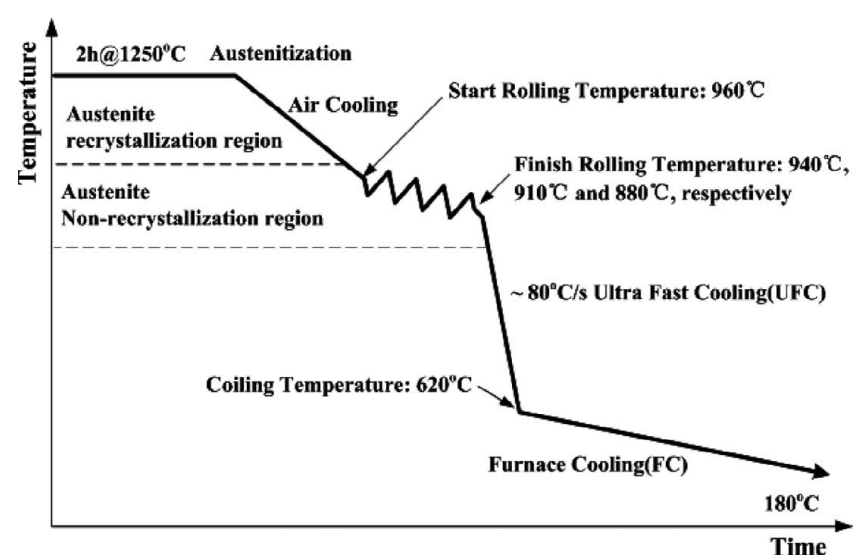

Fig. 1. Schematic diagram of thermo-mechanical controlled processing (TMCP).
$55)$.

The electron backscatter diffraction (EBSD) scans were performed along the transverse cross-section to investigate microstructural factors that influence the mechanical properties. Samples for EBSD were polished in an electronlyte consisting of $12.5 \%$ perchloric acid, $81.25 \%$ absolute ethyl alcohol and $6.15 \%$ water at $25^{\circ} \mathrm{C}$ using a voltage of $25 \mathrm{~V}$ for $25 \mathrm{~s}$.

In order to observe the precipitates distribution, transmission electron microscopy (TEM) studies were carried out using FEI Tecnai $G^{2}$ F20 equipped with a field emission gun operated at $200 \mathrm{kV}$, together with energy dispersive $\mathrm{X}$-ray spectroscopy (EDS). Thin foil samples were prepared by mechanically thinning samples to $0.05 \mathrm{~mm}$ by abrasion on $\mathrm{SiC}$ papers and then electro-polishing using a mixture of $12.5 \%$ perchloric acid and $87.5 \%$ ethanol at $-30^{\circ} \mathrm{C}$ with a voltage of $32 \mathrm{~V}$.

Tensile samples with gauge length of $50 \mathrm{~mm}$, width of $12.5 \mathrm{~mm}$ and thickness of $6 \mathrm{~mm}$ were machined along the rolling direction, and were tested at room temperature at a crosshead speed of $3 \mathrm{~mm} / \mathrm{min}$ by a CMT5105-SANS computerized tensile testing machine.

Charpy impact tests were performed in a JBW-500 impact testing machine with the maximum capacity of $300 \mathrm{~J}$ at three different temperatures: $-20^{\circ} \mathrm{C},-40^{\circ} \mathrm{C}$ and $-60^{\circ} \mathrm{C}$. The Charpy samples were machined from the plates along the rolling direction, and subsize samples with $5 \times 10 \times$ $55 \mathrm{~mm}^{3}$ were obtained. Samples with a thickness of $5 \mathrm{~mm}$ are within the range of applicability of the proportionality rule: ${ }^{21)}$

$$
K_{v 10}=\frac{10}{B} K_{v B}
$$

Where $K_{v 10}$ and $K_{v B}$ are the impact energy for samples which are $10 \mathrm{~mm}$ or $B \mathrm{~mm}$ thick, respectively. The fracture morphologies and crack propagation process of Charpy impact test samples were observed by SEM and EBSD, respectively.

\section{Results and Discussion}

\subsection{Microstructure Characteristics with Various Fin- ish Rolling Temperatures}

\subsubsection{Microstructural Evolution}

Figure 2 shows the optical images of the three steel specimens at the finish rolling temperatures of $940^{\circ} \mathrm{C}, 910^{\circ} \mathrm{C}$ and $880^{\circ} \mathrm{C}$. The SEM and TEM micrographs of steels are shown in Figs. 3 and 4, respectively. All the specimens were finish rolled in the austenite region and then fast cooled to the ferrite region. For A940, the microstructure was mainly composed of uneven quasi-polygonal ferrite, with a few acicular ferrite grains containing high density of dislocations (Fig. 4(a)). When the finish rolling temperature was decreased to $910^{\circ} \mathrm{C}$ (A910), the average grain size of quasi-polygonal ferrite reduced to $7.2 \pm 0.5 \mu \mathrm{m}$ from $9.0 \pm 2.3 \mu \mathrm{m}$, and large grains disappeared (Fig. 2(b)). For A880, the microstructure was dominant by acicular ferrite with the average diameter of ferrite grains $4.5 \pm 0.8 \mu \mathrm{m}$ (Fig. 2(c)). With the decrease of finish rolling temperature, the number of cementite particles distributed along the grain boundaries increased and its size reduced (Fig. 3). 


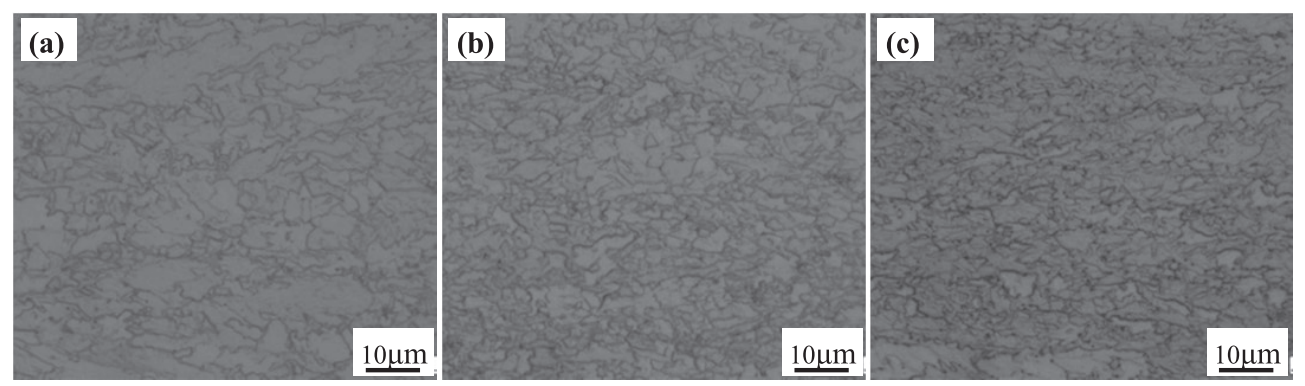

Fig. 2. Optical microstructures with various finish rolling temperatures of (a) A940, (b) A910 and (c) A880.
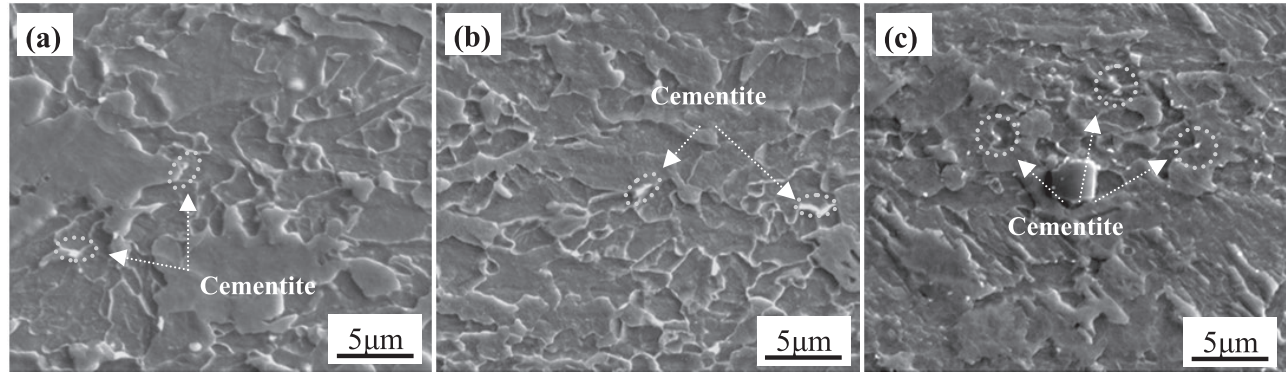

Fig. 3. SEM images with various finish rolling temperatures of (a) A940, (b) A910 and (c) A880.
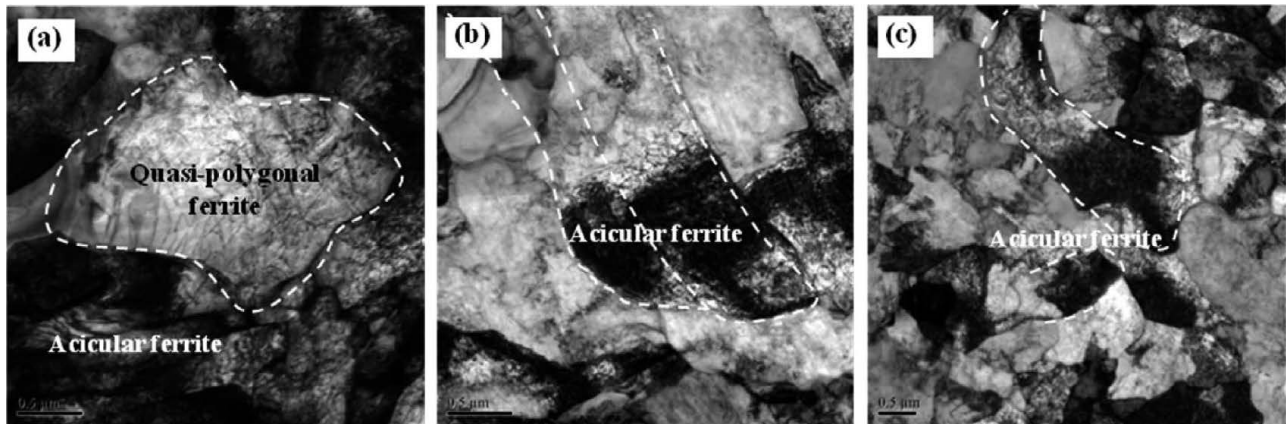

Fig. 4. TEM images with various finish rolling temperatures of (a) A940, (b) A910 and (c) A880.

With decrease in finish rolling temperature, the deformation was mainly performed in non- recrystallization region, which increased the deformation stored energy, substructures and dislocation density within austenite grains, provided greater driving force and nucleation sites for ferrite transformation, and caused refined ferrite grains. Additionally, fast cooling condition effectively maintained the hardened state of austenite, which suppressed the high temperature phase transformation and increased the undercooling, also made contributions to the grain refinement. The occurrence of acicular ferrite in A880, generally resulted from the insufficient diffusion of carbon atoms at the relatively lower finish rolling temperature. Simultaneously, the finer acicular ferrite grains provided more nucleation sites for the formation of cementite particles along the grain boundaries. ${ }^{22)}$ Moreover, the diffusion of carbon atoms at higher temperature was suppressed by ultra fast cooling after hot rolling, so that carbon atoms segregated at the grain boundaries and precipitated as cementite particles during the coiling simulation process. The smaller the ferrite grain size is, the shorter distance carbon atoms are to diffuse from intragranular to grain boundary. As a consequence, cementite particles were refined and well distributed along the ferrite grain boundaries observed in Fig. 3(c).
The EBSD results of the three experimental steels with different finish rolling temperatures are presented in Fig. 5. The low-angle grain boundaries with misorientation in the range of $2^{\circ}$ to $15^{\circ}$ are represented with red lines and high-angle grain boundaries greater than $15^{\circ}$ with black lines. Figure 5(d) plots the misorientation angle distributions obtained from specimens at the finish rolling temperatures of $940^{\circ} \mathrm{C}, 910^{\circ} \mathrm{C}$ and $880^{\circ} \mathrm{C}$. The profile of misorientation distribution is the typical one for ferritic microstructures. ${ }^{23)}$ The shape could be explained by the crystallographic relationship between the ferrite and the prior austenite. Based on the diffusion-controlled transformation, the grain boundary distribution originates from the Kurdjumov-Sachs orientation relationship between ferrite and prior austenite, or the variant selection. The result shows that the numbers of both grain refinement and substructure increase as the finish rolling temperature decreases, especially from $940^{\circ} \mathrm{C}$ to $880^{\circ} \mathrm{C}$. In other words, both high-angle grain boundaries and lowangle grain boundaries per unit area increase with decrease in finish rolling temperature. This also can be attributed to the grain refinement and increasing dislocations, produced at low finish rolling temperatures.

Figure 6 shows the orientation maps along rolling direction (RD) and the corresponding inverse pole figures parallel 

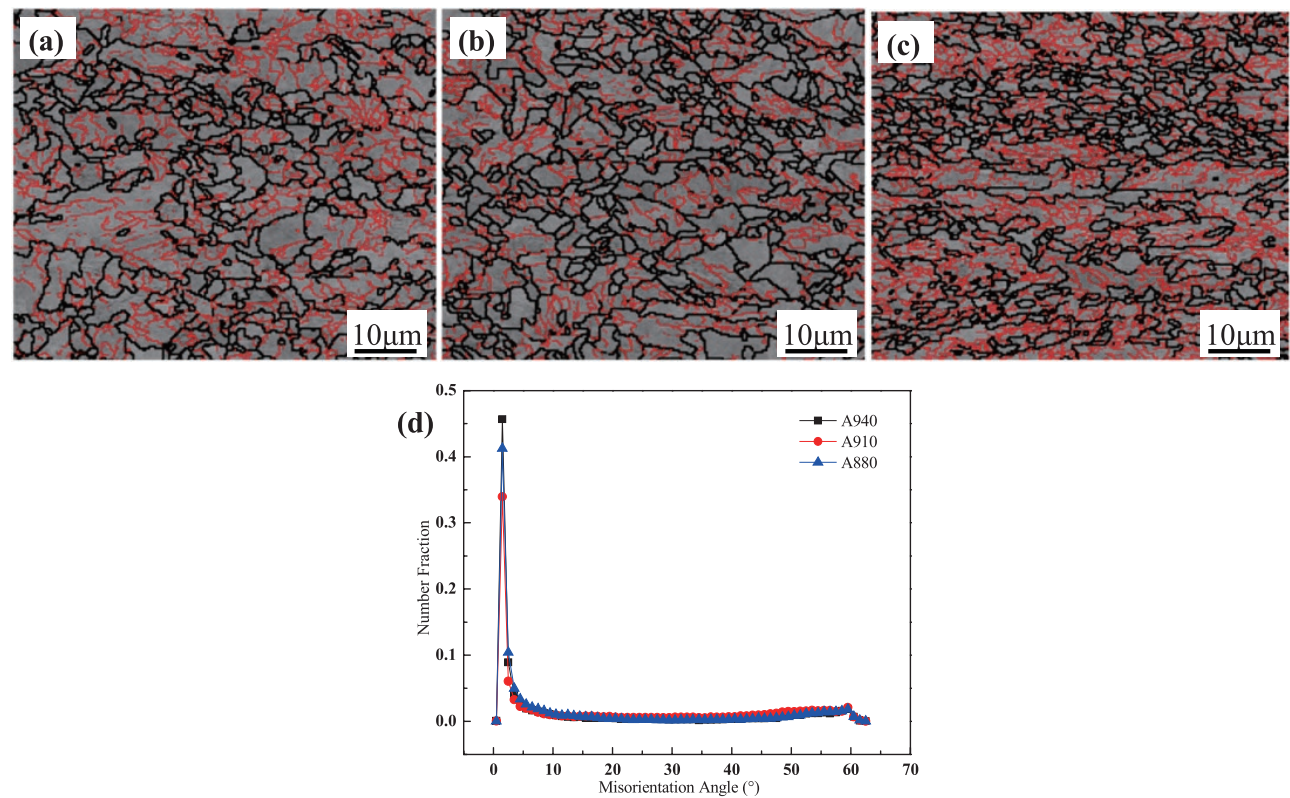

Fig. 5. Misorientation distribution maps of grain boundaries with various finish rolling temperatures of (a) A940, (b) A910, (c) A880 and (d) the misorientation angle distributions. (Online version in color.)
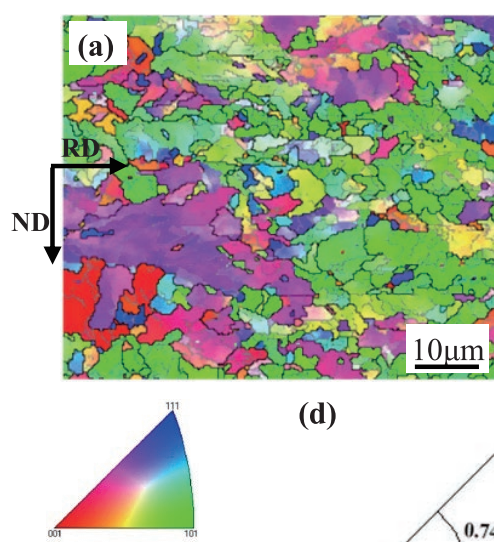
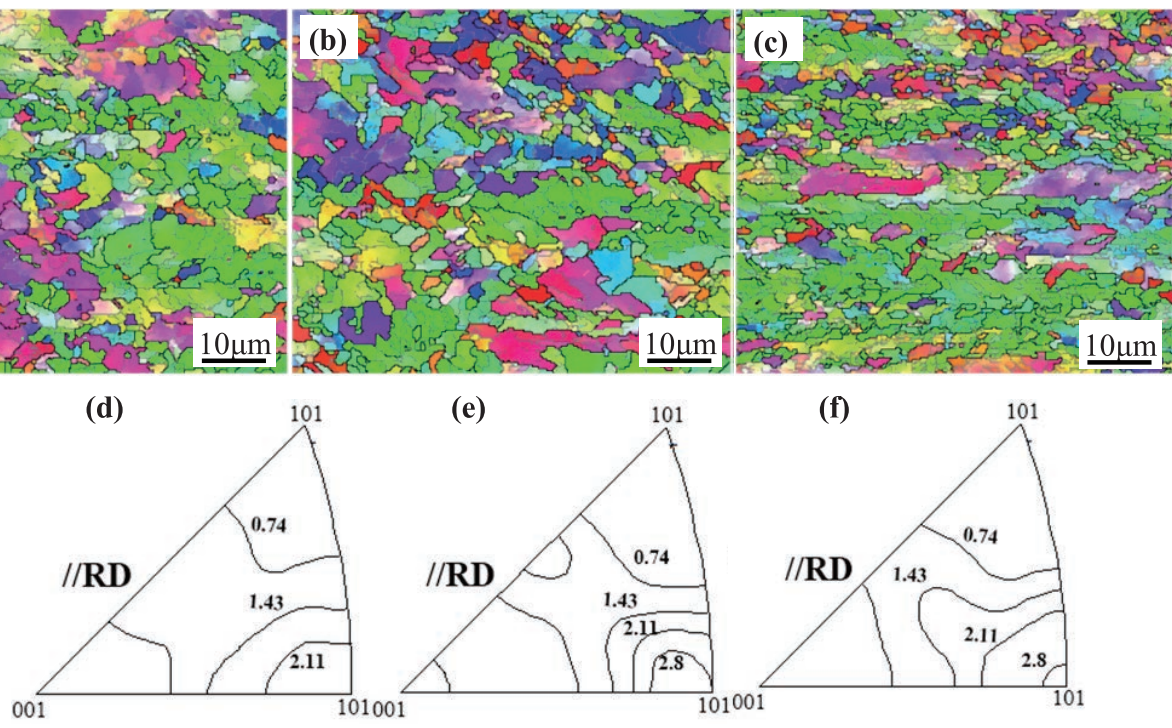

Fig. 6. Orientation maps and inverse pole figures with finish rolling temperatures of (a)/(d) A940, (b)/(e) A910 and (c)/(f) A880 (RD - rolling direction, ND - normal direction). (Online version in color.)

to the RD. The $\alpha$-fiber texture $\mathrm{RD} / /<110>$ was more prominent in Fig. 6. The high $\alpha$-fiber texture has been observed in the hot rolled API X100 pipeline steel and warm-rolled carbon steel. ${ }^{24,25)}$ It was reported that the intensity of this texture significantly increased in X100 pipeline steel when the finish rolling temperature decreased from more than $1100^{\circ} \mathrm{C}$ to $750-810^{\circ} \mathrm{C}^{24)}$ The intensity of the $\alpha$-fiber texture in warm-rolled low carbon steel was high and also increased with decrease in rolling temperature. ${ }^{25,26)}$ However, the intensity of the $\alpha$-fiber texture $\mathrm{RD} / /<110>$ was relatively low and did not change significantly with finish rolling temperature in this study, which may be attributed to the high rolling temperature and the relatively small changes of finish rolling temperature.

\subsubsection{Precipitation Behavior}

The TEM micrographs and energy dispersive spectros- copy (EDS) spectra of precipitates with different finish rolling temperatures are presented in Fig. 7, showing that random precipitation occurred for A940, A910 and A880 specimens. All the precipitates had a spherical shape and their chemical compositions were analyzed to be $\mathrm{Ti}, \mathrm{Nb}$ and $\mathrm{C}$; majority of the precipitates were identified as $(\mathrm{Nb}, \mathrm{Ti}) \mathrm{C}$ particles (Fig. 6(d)). The size and distribution of carbides were significantly affected by the finish rolling temperature. For A940, nanometer sized fine carbides with $6.0 \pm 1.8 \mathrm{~nm}$ were uniformly precipitated without clustering. For A910 and A880 samples, the average sizes of precipitates were $6.0 \pm 1.1 \mathrm{~nm}$ and $6.2 \pm 0.9 \mathrm{~nm}$, respectively. It is noted that A940 was almost compatible with other specimens, in terms of the size of $(\mathrm{Nb}, \mathrm{Ti}) \mathrm{C}$ particles. The number density of $(\mathrm{Nb}, \mathrm{Ti}) \mathrm{C}$ particles precipitated in these three experimental steels were the statistical results of particle number in per unit $\mu \mathrm{m}^{2}$. The number densities of $(\mathrm{Nb}, \mathrm{Ti}) \mathrm{C}$ particles in 
A940, A910 and A880 were $3856 \pm 68 / \mu^{2}, 1824 \pm 27 / \mu \mathrm{m}^{2}$ and $1000 \pm 15 / \mu \mathrm{m}^{2}$, respectively, which reflected the volume fraction of precipitates. The results indicate that the volume fraction of $(\mathrm{Nb}, \mathrm{Ti}) \mathrm{C}$ decreased remarkably with the decrease in finish rolling temperature.

The finish rolling temperature is a determinant of precipitation in ferrite. ${ }^{8,16)}$ It is known that the accumulation of dislocations during the rolling process can bring about strain induced precipitation by promoting the precipitation kinetics. However, the random precipitation after ferrite transformation is preferred as the main precipitation mechanism rather than strain induced precipitation. Because the strain induced precipitation is easy to coarsen, while the size of random precipitation was almost consistent with each other, as previously mentioned. When the finish rolling temperature is high, the precipitation in high temperature region can be effectively inhibited by ultra fast cooling following the hot rolling process, subsequently, leading to the increase in chemical supersaturation degree of microalloying elements in ferrite. Thus, the driving force for precipitation in
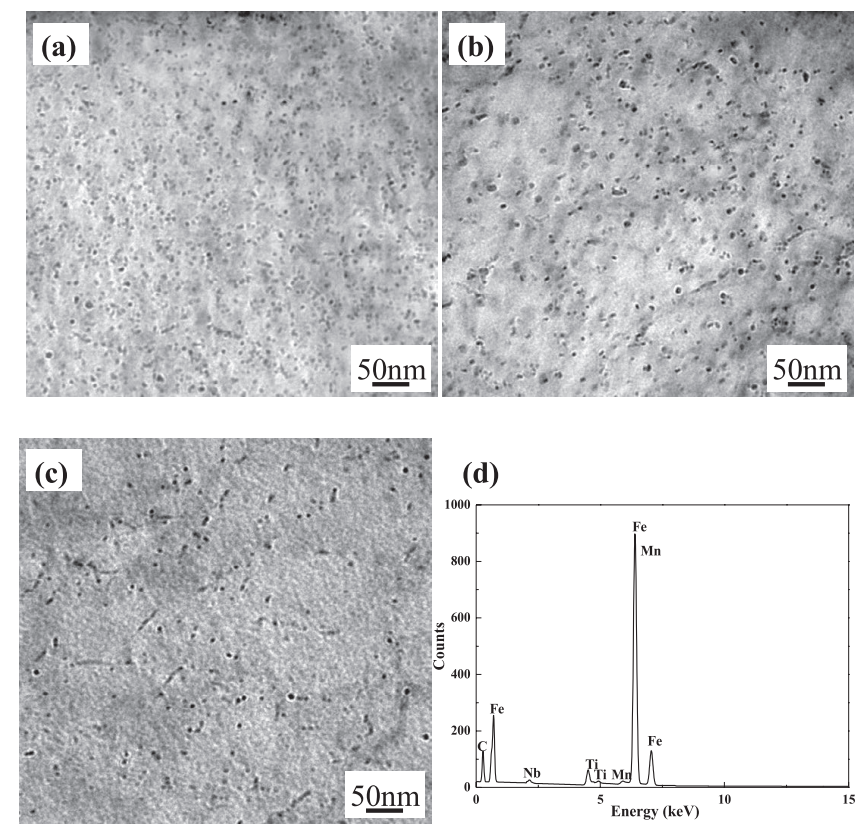

Fig. 7. The TEM morphologies of precipitates with various finish rolling temperatures of (a) A940, (b) A910, (c) A880 and (d) EDS spectrum of precipitates. ferrite phase is increased, which eventually promotes the precipitation in ferrite phase. Thus, the volume of carbides distributed in ferrite matrix of A940 is larger as compared to other two steels (see in Fig. 7), leading to larger precipitation strengthening contribution to the yield strength.

\subsubsection{Mechanical Properties}

Room temperature tensile test results are provided in Fig. 8(a), including yield strength $\left(\mathrm{R}_{\mathrm{p} 0.2}\right)$, tensile strength $\left(\mathrm{R}_{\mathrm{m}}\right)$, and elongation (EL). All the specimens show yield strength of above $710 \mathrm{MPa}$, tensile strength of above $750 \mathrm{MPa}$ and elongation of above $19 \%$, regardless of rolling conditions. The values of $R_{p 0.2}, R_{m}$ and EL first slightly increase with increasing finish rolling temperature, reaches the maximum at $910^{\circ} \mathrm{C}$, and then decreases. Irrespective of this, the difference in these values was small. The precipitation strengthening at high finish rolling temperature may compensate for the reduction of yield strength due to the large ferrite grain size.

In Fig. 8(b), the Charpy impact energy ( $v E)$ is plotted as a function of test temperature. There is a large difference in impact absorbed energy $(v E)$ of experimental steel for different finish rolling temperatures. At an identical impact test temperature, the value of $v E$ increases with decreasing finish rolling temperature. In correspondence to the effect of test temperature, for A940, the value of $v E$ first significantly reduces from $64 \mathrm{~J}$ to $11 \mathrm{~J}$, then remained almost similar when the test temperature decreases to $-60^{\circ} \mathrm{C}$; for A910, the value of $v E$ decreases linearly from $72 \mathrm{~J}$ to $9 \mathrm{~J}$ with decreasing test temperature; for A880, the value of $v E$ first reduces a small extent from $128 \mathrm{~J}$ to $120 \mathrm{~J}$, then decreases significantly with decrease in impact test temperature. According to the previous studies, ${ }^{24-31)}$ the Charpy impact energy is influenced by the texture of the material and the kind, volume fraction, size and morphology of the phases. It has been reported that the $\alpha$-fiber $\mathrm{RD} / /<110>$ can lead to the delamination and effectively enhance the lowtemperature toughness, especially for warm-rolled carbon steel. ${ }^{25,26)}$ The $\alpha$-fiber $\mathrm{RD} / /<110>$ was also observed in the specimens (Fig. 6) and considered to be conducive to the low-temperature toughness. However, the changes of finish rolling temperature from $940^{\circ} \mathrm{C}$ to $880^{\circ} \mathrm{C}$ did not cause apparent difference in the intensity of $\alpha$-fiber $\mathrm{RD} / /<110>$. Thus, it is considered that the effect of $\alpha$-fiber on Charpy
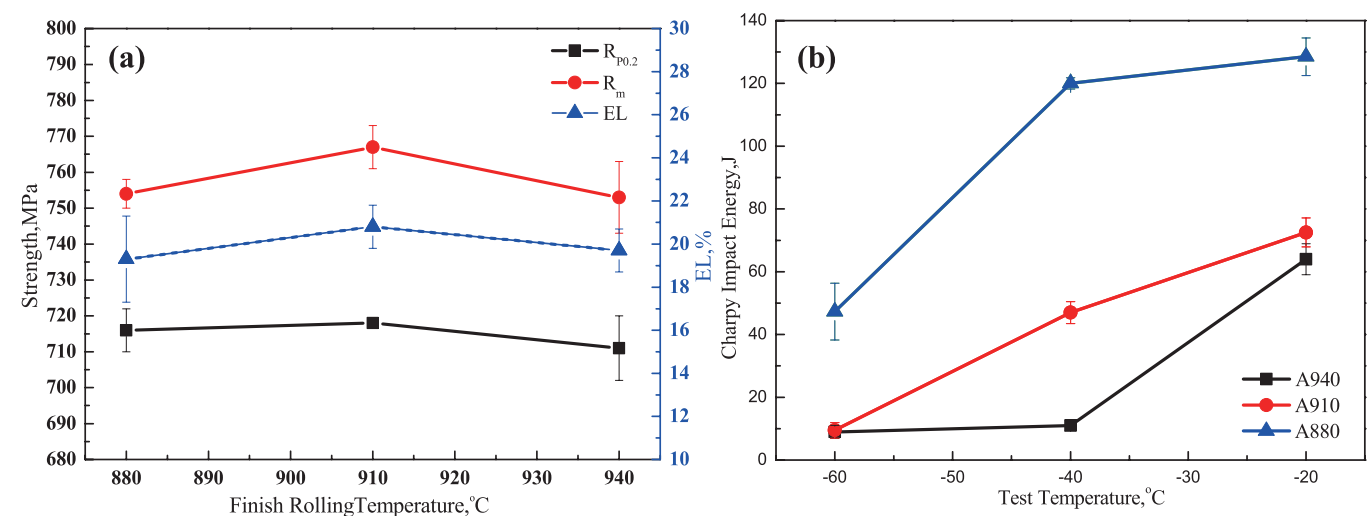

Fig. 8. Relationships between mechanical properties and finish rolling temperature of experimental steels (a) the relationship between strength, elongation and finish rolling temperature, (b) the relationship between impact energy and test temperature. (Online version in color.) 
impact energy in this study can be limited. As the steel mainly has a single ferrite phase with quasipolygonal shape, the factors considered to be influential to impact properties are the ferrite grain size, dislocation structures and precipitation of carbides. The small grain size of steels enhances the Charpy impact energy. ${ }^{30)}$ In addition, inhomogeneous grain size impairs the mechanical properties, especially the toughness. On the other hand, dislocation structures inside ferrite grains improves the impact toughness. However, the precipitation carbides deteriorate the impact toughness. ${ }^{31,32)}$ On the basis of the microstructural characteristics of three specimens with different finish rolling temperature, the results of the lowest impact toughness of A940 and the highest impact toughness of A880, can be understood. Moreover, the refined cementite particles and the occurrence of acicular ferrite with relatively small effective grain size at finish rolling temperature $880^{\circ} \mathrm{C}$ also improve the impact toughness.

\subsection{Fracture Mechanism at Low Temperature}

\subsubsection{Micrographs of Fracture Surface}

The overall fracture surfaces and detailed SEM fractographic examinations were carried out on the Charpy impact test specimens, for the purpose of evaluating possible crack initiation sites and microstructural features in their vicinity. Figure 9 shows SEM fractographs of the Charpy impact samples fractured at $-40^{\circ} \mathrm{C}$. The fracture surface of sample A940 was completely covered by cleavage fracture with relatively large size of unit cleavage facet (Figs. 9(a)/9(e)), which probably stem from the large ferrite grain boundary nearby the cementites. For A910, deep grooves exist on the fracture surface indicated by arrows in Fig. 9(b); although the main fracture mode is brittle for A910, there are still some small dimples on tear ridges along the cleave fracture (see Fig. 9(f)), which largely contribute to the dissipated energy during crack propagation and at crack arrest. ${ }^{33)}$ For A880, the fracture mechanism is dif- ferentiated from the other two samples, even though there is significant delamination marked by white arrows similar to A910 (see Fig. 9(c)). The fracture surface of A880 is typical ductile fracture behavior with deep and uniformly distributed dimples, which indicates the fracture was associated with micro-void growth and coalescence. ${ }^{34)}$ Despite the grain size and precipitation are influencial to improving toughness, the delamination also plays a role in ductile-tobrittle transition region, ${ }^{35)}$ and often considered as a fracture energy absorption process and increasing toughness. Additionally, delamination produces dimples, characteristic of ductile fracture shown in Fig. $9(\mathrm{~g})$. Therefore, even though the fracture mode of A940 and A910 is brittle fracture, the impact energy of A910 is greater than A940, owing to the delamination. The fractographs are consistent with Charpy impact energy of the three specimens.

\subsubsection{Cracks Initiation and Propagation}

Cracks initiate at some regions with stress concentration, where applied loading conditions cause the local stress to exceed the local strength of the material. ${ }^{36,37)}$ These regions may be due to macroscopic discontinuities (a geometric notch or other change in cross section) and/or microscopic discontinuities (an inclusion or second phase). The common locations of the incipient cracks initiation are second phase, grain boundary and dislocation pile-up. ${ }^{38,39)}$

The second phases in the studied steels were cementite particles and $(\mathrm{Nb}, \mathrm{Ti}) \mathrm{C}$ particles. The strength of these particles in the steels was higher than that of ferrite matrix, and there was partial coherency or incoherency orientation between these particles and the matrixes. The deformation discontinuities during impact testing would cause stress concentration in the particle/ferrite matrix interfaces, resulting in crack formation. Except the deformation discontinuities, cementite particles precipitated at the grain boundaries could simultaneously pin the interface and dislocations, ${ }^{40)}$ which could also cause stress concentration in the cementite
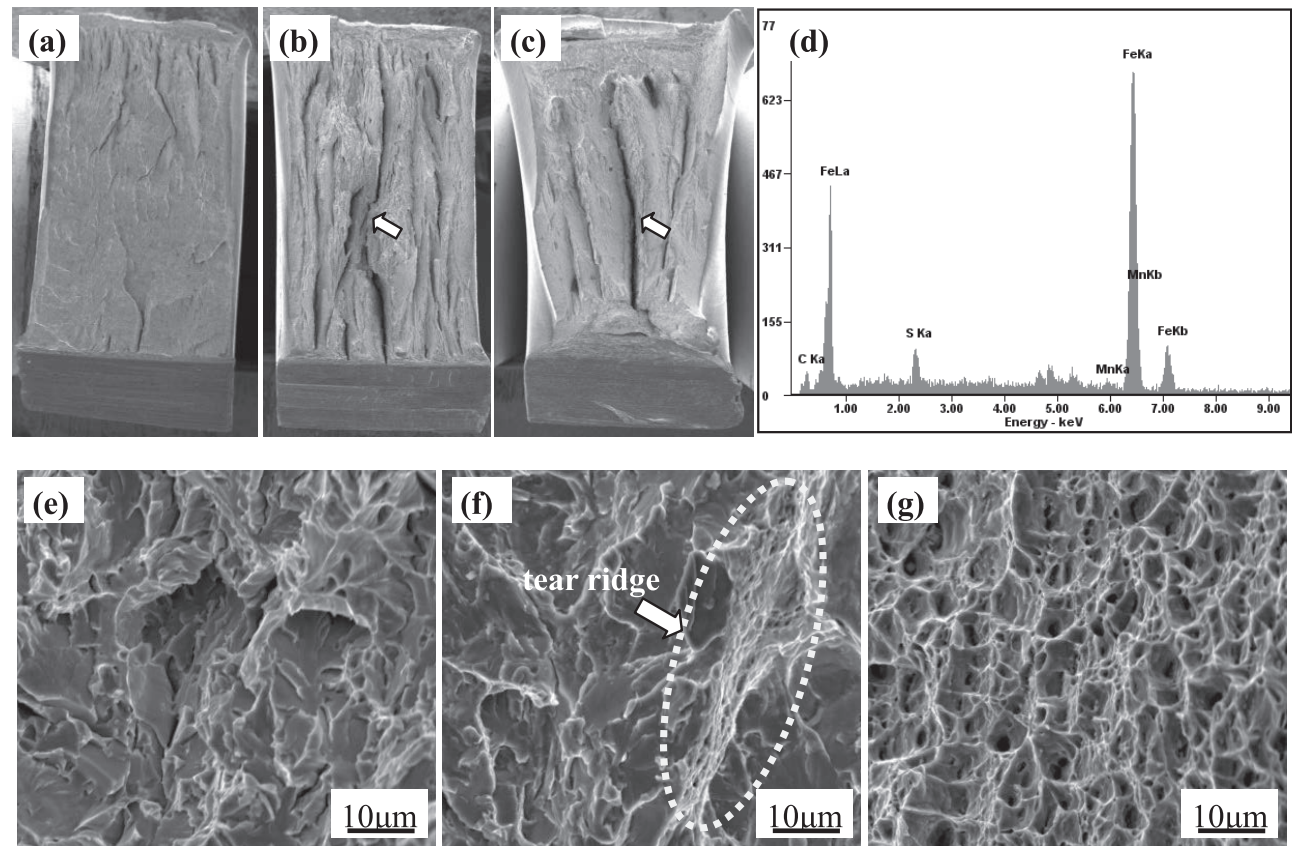

Fig. 9. Fracture surfaces at the testing temperature $-40{ }^{\circ} \mathrm{C}$ with various finish rolling temperatures of (a) and (e) A940, (b) and (f) A910, (c) and (g) A880, and (d) EDX of inclusions at the bottom of dimple. 
particle/ferrite interfaces. Even though cementite particles existed in all the studied steels, the size of cementite particles in A940 and A910 was larger than that of A880 (Fig. 3 ). The deformation discontinuities and stress concentration were relatively easy to form around the large cementite particles distributed at the grain boundaries, as shown in A940 and A910. Additionally, the cementite particles located in ferrite grain boundaries was easier to form cracks than that of small $(\mathrm{Nb}, \mathrm{Ti}) \mathrm{C}$ particles.

Grain boundary is a barrier for dislocation motion, and dislocations in the interior of grains pile up at the grain boundary, to generate a stress concentration at the grain boundary. The coarse grain exhibits larger pile-ups than that of fine ferrite grains. ${ }^{41,42)}$ The result indicates that the average grain size of ferrite in A940 and A910 was larger than that of $A 880$ (Fig. 2). Therefore, the number of dislocation pile-ups in A940 and A910 is larger than that of A880, leading to greater stress concentration in A940 and A910. As a result, the cementite particle/grain boundary interfaces and dislocation pile-ups at the ferrite grain boundaries were the preferred locations of incipient crack initiation in A940, similar with A910. In the A880, the number of dislocation pile-ups in ferrite caused little stress concentration, which may be insufficient to crack initiations, verified in Fig. 11(c). Therefore, the debonding at the second phase particle/matrix interfaces was the dominant mechanism of incipient crack initiation in A880, and eventually evolved into microvoids.

The propagation behaviors of secondary cracks in the cross-sectional areas beneath the fracture surface are presented in Figures $\mathbf{1 0}$ and 11. The results show that both intergranular cracks and transgranular cracks exist in A940 and A910. Although the lattice of ferrite grains is often more ductile than grain boundaries, brittle transgranular fracture also occurred in Fig. 10(a). It indicates that the propagation of transgranular crack was arrested by high angle grain boundaries (greater than $15^{\circ}$ ), which is consistent with the research of A. Iza-Mendia. ${ }^{23)}$ However, the propagation path in A940 is almost straight, and very low plastic strains even near the cracks can be observed. Fig. 10(b) shows the crack changes its propagation direction as it meets the neighboring grains with another orientation in A910, which can consume the energy of crack. The plastic deformation elongates the ferrite grains of A910, shown in Fig. 11(b). The development of cleavage fracture includes two stages: generation of microcracks around a grain and spreading of the crack. ${ }^{43,44)}$ The development of microcracks is based on the movement of dislocations, which were induced by plastic deformation and accumulated between two slip bands, leading to a microcrack on the cleavage plane (001) of the ferrite lattice. Additionally, the grain boundary strength or phase boundary strength is lower than the crystalline strength. Therefore, intergranular fractures in steels with smaller grain size occur more easily. If the grain boundaries are weakened by precipitations or cementite, the cleavage fracture can also appear along the grain boundaries as an intergranular cleavage fracture. In A880, some microvoids appear in the ferrite matrixes with obviously plastic strains reflected by the high density of grain boundaries, which were pinned by high density dislocations mainly caused by deformation; and the growth of microvoids usually turns to another direction (shown in Fig. 11(c)), when they encounter with high angle grain boundaries, leading to energies consumption. ${ }^{44}$ Therefore, the edges of microvoids passivate and are difficult to propagate continuously. The shape of microvoids is elongated due to the plastic strains. Consequently, the microvoids grow and polymerize with others. Due to the high toughness of A880, microcracks were hardly observed beneath the fracture surface.
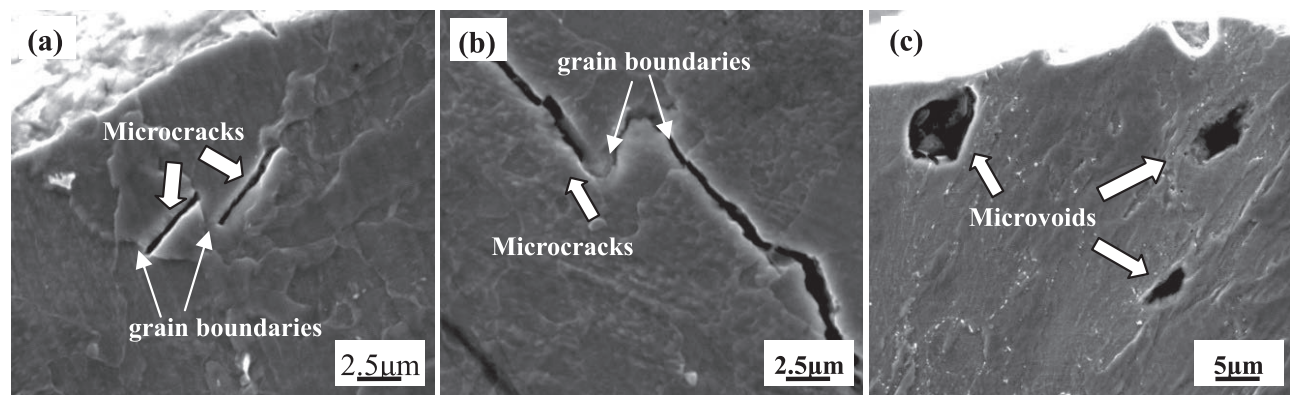

Fig. 10. The secondary cracks underneath the fracture surface of specimens at testing temperature of $-40^{\circ} \mathrm{C}$ for various finish rolling temperatures of (a) A940, (b) A910, (c) A880.
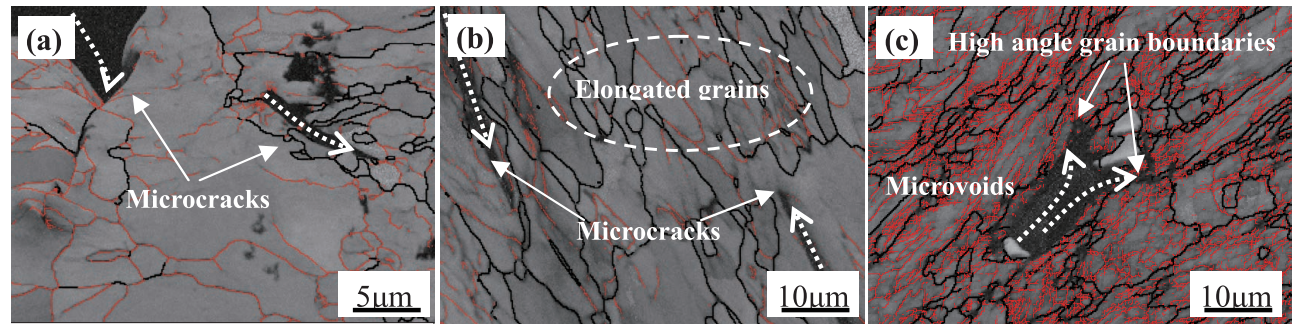

Fig. 11. Image quality maps with grain boundary misorientation distribution underneath the fracture surface of specimens at testing temperature of $-40^{\circ} \mathrm{C}$ for various finish rolling temperatures of (a) A940, (b) A910, (c) A880. (Online version in color.) 


\section{Conclusions}

In this study, the microstructural characteristics and mechanical properties of $\mathrm{Nb}-\mathrm{Ti}$ ferritic high strength steel at three different finish rolling temperatures were investigated. The results have been used to elucidate the corresponding fracture mechanism. The following are the main conclusions:

(1) The microstructure of steel finish rolled at higher temperature, primarily consisted of polygonal ferrite and few large elongated grains, while acicular ferrite and refined cementite particles occurred along boundaries at lower finish rolling temperature. The grain size was decreased and the fraction of high-angle grain boundaries $\left(>15^{\circ}\right)$ per unite area was significantly increased with decrease in finish rolling temperature.

(2) Random distribution of $(\mathrm{Nb}, \mathrm{Ti}) \mathrm{C}$ precipitates were observed by TEM in the ferrite matrix for the three rolling conditions. The volume fraction of precipitates significantly increases with the increasing finish rolling temperature, followed by ultra fast cooling. The size of precipitates was in the narrow range of $6.0-6.3 \mathrm{~nm}$.

(3) The values of yield strength, tensile strength, and elongation are greater than $710 \mathrm{MPa}, 750 \mathrm{MPa}$ and $19 \%$, respectively, and the fluctuations of these values are relatively small with decreasing finish rolling temperature. Precipitation strengthening compensates for the reduction in yield strength caused by the large ferrite grain size.

(4) The impact toughness decreases with the increasing finish rolling temperature. When the impact testing temperature is $-40^{\circ} \mathrm{C}$, the plates at high finish rolling temperature is brittle fracture with the microcracks propagating along the grain boundaries, while the low finish rolling temperature leads to ductile fracture with microvoid coalescence.

\section{Acknowledgements}

This work was financially supported by the National Natural Science Foundation of China (No. 51234002) and the National Science Foundation of China for Young Scholars (No. 51204049). The authors are grateful to the kind support from China Scholarship Council (CSC) (No. 201506080057).

\section{REFERENCES}

1) T. Senuma: ISIJ Int., 41 (2001), 520.

2) J. M. Zhang, W. H. Sun and H. Sun: J. Iron Steel Res. Int., 17 (2010), 63.

3) G. Jha, S. Das, A. Lodh and A. Haldar: Mater. Sci. Eng. A, 552 (2012), 457.

4) Y. W. Kim, S. W. Song, S. J. Seo, S. G. Hong and C. S. Lee: Mater. Sci. Eng. A, $\mathbf{5 6 5}$ (2013), 430.

5) N. J. Kim, A. J. Yang and G. Thomas: Metall. Trans. A, 16A (1985), 471.
6) Y. Funakawa, T. Shiozaki, K. Tomita, T. Yamamoto and E. Maeda: ISIJ Int., 44 (2004), 1945.

7) K. Seto, Y. Funakawa and S. Kaneko: JFE Tech. Rep., 10 (2007), 19

8) S. G. Hong, K. B. Kang and C. G. Park: Scr. Mater., 46 (2002), 163.

9) A. G. Kostryzhev, A. A. Shahrani, C. Zhu, S. P. Ringer and E. V. Pereloma: Mater. Sci. Eng. A, 581 (2013), 16.

10) A. G. Kostryzhev, A. A. Shahrani, C. Zhu, S. P. Ringer and E. V. Pereloma: Mater. Sci. Forum, 753 (2013), 431

11) J. Chen, F. Li, Z. Y. Liu, S. Tang and G. D. Wang: ISIJ Int., 53 (2013), 1070.

12) J. C. Bao, J. X. Ma, J. Zhao and B. Q. Ning: Adv. Mater. Res., 652-654 (2013), 967.

13) R. D. K. Misra, H. Nathani, J. E. Hartmann and F. Siciliano: Mater. Sci. Eng. A, 394 (2005), 339

14) J. Hu, L. X. Du and J. J. Wang: Mater. Sci. Eng. A, 554 (2010), 79.

15) X. N. Wang, Y. F. Zhao, B. J. Liang, L. X. Du and H. S. Di: Steel Res. Int., 84 (2013), 402.

16) Q. Y. Sha, G. Y. Li, L. F. Qiao and P. Y. Yan: Proc. Sino-Swedish Structural Materials Symp., J. Iron and Steel Research Int., China, (2007), 316.

17) C. Y. Chen, C. C. Chen and J. R. Yang: Mater. Charact., 88 (2014), 69

18) Y. W. Kim, J. H. Kim, S. G. Hong and C. S. Lee: Mater. Sci. Eng. A, 605 (2014), 244.

19) J. Chen, M. Y. Lv, S. Tang, Z. Y. Liu and G. D. Wang: ISIJ Int., 54 (2014), 2926.

20) S. Tang, Z. Y. Liu, G. D. Wang and R. D. K. Misra: Mater. Sci. Eng. A, $\mathbf{5 8 0}$ (2013), 257.

21) B. Mintz, G. Peterson and A. Nassar: Ironmaking Steelmaking, 21 (1994), 215

22) F. Q. Ji, C. N. Li, S. Tang, Z. Y. Liu and G. D. Wang: Mater. Sci. Technol., 31 (2015), 695.

23) A. Iza-Mendia and I. Gutierrez: Mater. Sci. Eng. A, 561 (2013), 40.

24) X. L. Yang, Y. B. Xu, X. D. Tan and D. Wu: Mater. Sci. Eng. A, 641 (2015), 96

25) T. Inoue, F. X. Yin, Y. Kimura, K. Tsuzaki and S. Ochiai: Mater. Trans. A, 41A (2010), 341.

26) D. L. Bourell and O. D. Sherby: Metall. Trans. A, 14A (1983), 2563.

27) A. Rossoll, C. Berdin and C. Prioul: Int. J. Fract., 115 (2002), 205.

28) S. Y. Shin, S. Y. Han, B. C. Hwang, C. G. Lee and S. H. Lee: Mater. Sci. Eng. A, 517 (2009), 212

29) S. Y. Han, S. Y. Shin, S. H. Lee, N. J. Kim, J.-H. Bae and K. Kim: Metall. Mater. Trans. A, 41 (2010), 329.

30) H. K. Sung, S. S. Sohn, S. Y. Shin, S. Lee, N. J. Kim and S. H. Chon: Mater. Sci. Eng. A, 541 (2012), 181.

31) H. F. Lan, L. X. Du and R. D. K. Misra: Mater. Sci. Eng. A, 611 (2014), 194.

32) B. Hwang, S. Lee, Y. M. Kim, N. J. Kim and J. Y. Yoo: Metall. Mater. Trans. A, 36A (2005), 1793.

33) E. Bouyne, H. M. Flower, T. C. Lindley and A. Pineau: Scr. Mater., 39 (1998), 295.

34) K. Chung, N. Ma, T. Park, D. Kim, D. Yoo and C. Kim: Int. J. Plast., 27 (2011), 1485

35) M. S. Joo, D. W. Suh, J. H. Bae and H. K. D. H. Bhadeshia: Mater. Sci. Eng. A, 546 (2012), 314

36) W. T. Becker and S. Lampman: ASM Handbook Vol. 11, ASM International, Materials Park, OH, (2002), 559.

37) J. Gurland and J. Plateau: Trans. ASM., 56 (1963), 442.

38) G. T. Hahn: Metall. Trans. A, 15A (1984), 947.

39) W. T. Becker and D. McGarry: ASM Handbook Vol. 11, ASM International, Materials Park, OH, (2002), 587.

40) F. Q. Ji, C. N. Li, S. Tang, Z. Y. Liu and G. D. Wang: Mater. Sci. Technol., 31 (2015), 695.

41) A. Naveed: PhD Thesis, Ruhr University Bochum, Germany, (2010), 91.

42) M. Zhang, P. S. Yang, Y. X. Tan, Y. Liu and S. P. Gong: Mater. Sci. Eng. A, 271 (1999), 390.

43) W. Bleck: Materials Characterisation-Textbook for RWTH Students, Department of Ferrous Metallurgy RWTH Aachen University, Aachen, (2012), 23.

44) J. Chen, S. Tang, Z. Y. Liu and G. D. Wang: Mater. Sci. Eng. A, 559 (2013), 241. 